venogram various structures, especially bones, are obliterated, allowing clearer visualization of the opacified vessels. If available, image intensification with television control and an automatic device for giving rapid serial films are helpful. But the procedure can give worthwhile results, as Kreel and Williams have noted, with only standard radiological equipment.

Trans-splenic portal venography undoubtedly gives a clearer picture of the portal vascular bed than arterio-portography. But selective arteriography can be performed when necessary on patients with portal hypertension and with a tendency to bleeding, when puncture of the spleen would be dangerous. It has the further advantage in that, if necessary, repeated injections may be made to obtain additional views. Hepatic arteriography may also give useful information on the site of swellings in the liver. With these two new techniques there seems no reason why doubt should exist nowadays about the state of the portal venous circulation in patients with portal hypertension.

\section{Toxicity of Drugs}

The possibility of toxic reactions from drugs has been of growing concern to doctors in recent years. ${ }^{1 .}$ Consequently the appearance of the first report of the Expert Committee on Drug Toxicity of the Association of the British Pharmaceutical Industry ${ }^{3}$ is of interest. The recent publication of the report of the Commission on Drug Safety of the American Pharmaceutical Manufacturers Association ${ }^{4}$ allows comparison of British and American ideas.

The first section of the British report covers general aspects of toxicity studies of new drugs. A more detailed discussion follows on such subjects as pharmacodynamic activity and tests of acute, subacute, and chronic toxicity. The last section deals with special studies, including the toxicity of drugs for local application, effects on reproduction, carcinogenicity, and interaction with other agents. The report draws attention to the possible toxicity of solvents, diluents, and other materials added to the drug itself, though many such materials have been used for many years and are generally regarded as safe. It emphasizes that all drugs can produce unwanted effects and that it is essential to determine the relation between the dose that causes them and that which elicits the desired therapeutic response. Clearly, as the American report points out, the criteria for considering a new compound for cancer chemotherapy are different from those that should be applied to a new analgesic.

There is now widespread agreement that rigid requirements for toxicity testing cannot be laid down and that attempts to do so are mistaken. This point is well made in the British report, where the study of each new drug is described as a research project in its own right. At the same time it is emphasized that there are certain minimal data which should be obtained whenever possible. While information from one animal species cannot necessarily be taken as valid for another, the committee maintains that experiments on a few species whose responses are widely known can give helpful information on the potential toxicity of a drug to man. Such an assumption is implicit in all experimental work with animals intended to yield information of value to medicine. Another useful feature of the report is the firm recommenda- tion that a reliable assessment of the potential toxicity of an agent to man depends more on close and careful observation of its action in the experimental animal than on the total number of animals used. The idea that large numbers of test animals give some kind of guarantee of the correctness of the results obtained has been losing ground since the publication of the critical review by J. M. Barnes and F. A. Denz in $1954^{\circ}$ and has been under renewed attack recently." It is gratifying, therefore, to find that both the British and the American reports give strong support for the reasoned and scientific rather than the mechanical rule-of-thumb approach to toxicity testing. This guiding principle is further emphasized in the British report by the recommendation that the species used for prolonged studies of toxicity should show a response to the drug which is relevant to its clinical effect. And the report also recommends that available knowledge of the metabolism of the drug in man should be used in an attempt to find laboratory animal species with similar metabolic pathways. However, this is not always possible owing to ethical or practical objections. The committee recommends that special attention should be given to the development of methods for detecting and estimating the drug and its metabolites in biological materials, so that metabolic studies in man and animals can be compared. Similar recommendations have been made by a W.H.O. Expert Committee on Food Additives.

As clinicians are only too well aware, minute doses of some drugs may produce reactions such as hypersensitivity and blood dyscrasias which have no resemblance to the ordinary effects of the drug. This type of serious sidereaction cannot be predicted by any existing animal tests and presents a challenge to experimental toxicology. The other two major problems are the working out of satisfactory tests for teratogenicity and for carcinogenicity. Since the thalidomide disaster attempts have multiplied to devise animal tests which will reveal potential human teratogenic activity of drugs, ${ }^{\circ}$ food additives, and pesticides, and an extensive bibliography has been compiled. ${ }^{9}$ It must be admitted that no satisfactory methods are yet available, and the American report is critical of the volume of work devoted to the problem. The British committee does make some recommendations on what may be regarded as minimal data, but emphasizes that they are provisional. Testing for carcinogenicity of drugs is also difficult. It is now widely held that this is the only real reason for the long-term feeding studies carried out on animals, and the question arises of which drugs should be tested in this way. The committee recommends that it is prudent to investigate the potential carcinogenicity of new drugs intended to be given clinically for long periods, and few would quarrel with this. Obvious examples are the oral contraceptives. As a guide to the testing of drugs in animals for their potential toxicity to man this report should be valuable, and the committee is to be congratulated on its brief, lucid, and practical presentation.

Brit. med. F., 1962, 2, 461

2 Ibid., 1963, 1, 1250.

${ }^{3}$ First Report of the Expert Committee on Drug Toxicity, 1964. Association of the British Pharmaceutical Industry, London.

1 Report of the Commission on Drug Safety, 1964. Pharmaceutical Manufacturers Association, U.S.A.

Barnes, J. M., and Denz, F. A., Pharmacol. Rev., 1954, 6, 191.

"Bein, H. J., in Viewpoints on the study of drug toxicity. Proceeding: of the European Society for the Study of Drug Toxicity, 1963, 2, 15.

Sixth Report of the Joint F.A.O./W.H.O. Expert Committee on Food Additives, 1962. World Health Organization, Geneva.

$\checkmark$ Brit. med. F., 1964, 1, 195.

- Fave, A., Thérapie, 1964. 19, 43. 